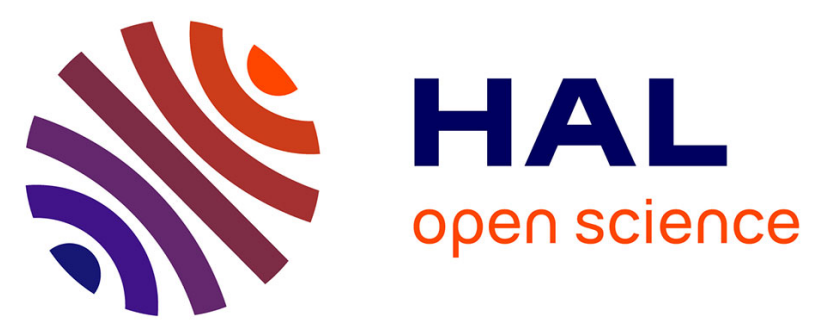

\title{
Resistance to mold development assessment of bio-based building materials
}

M. Viel, F. Collet, Y. Lecieux, M.L.M. François, V. Colson, Christophe Lanos, A. Hussain, M. Lawrence

\section{- To cite this version:}

M. Viel, F. Collet, Y. Lecieux, M.L.M. François, V. Colson, et al.. Resistance to mold development assessment of bio-based building materials. Composites Part B: Engineering, 2019, 158, pp.406-418. 10.1016/j.compositesb.2018.09.063 . hal-01903670

\section{HAL Id: hal-01903670}

\section{https://hal-univ-rennes1.archives-ouvertes.fr/hal-01903670}

Submitted on 9 Nov 2018

HAL is a multi-disciplinary open access archive for the deposit and dissemination of scientific research documents, whether they are published or not. The documents may come from teaching and research institutions in France or abroad, or from public or private research centers.
L'archive ouverte pluridisciplinaire HAL, est destinée au dépôt et à la diffusion de documents scientifiques de niveau recherche, publiés ou non, émanant des établissements d'enseignement et de recherche français ou étrangers, des laboratoires publics ou privés. 


\section{Resistance to mold development assessment of bio-based building}

\section{2 materials}

3 Marie Viel ${ }^{\mathrm{a}, *}$, Florence Collet ${ }^{\mathrm{a}}$, Yann Lecieux ${ }^{\mathrm{b}}$, Marc François $^{\mathrm{b}}$, Valentin Colson ${ }^{\mathrm{a}, \mathrm{c}}$, Christophe Lanos ${ }^{\mathrm{a}}$,

$4 \quad$ Atif Hussain $^{d}$ and Mike Lawrence ${ }^{d}$

5 a Université de Rennes, Laboratoire Génie Civil et Génie Mécanique, BP 90422, Rennes,

6 France

${ }^{b}$ Université de Nantes, Institut de Recherche en Génie Civil et Mécanique, BP 92208, Nantes,

France

${ }^{c}$ CAVAC Biomatériaux, Le Fief Chapitre, Sainte Gemme la Plaine, France

${ }^{d}$ BRE Centre for Innovative Construction Materials, Department of Architecture and Civil Engineering, University of Bath, BA2 7AY, United Kingdom

*Corresponding author: marie.viel@univ-rennes1.fr

\section{Abstract}

Nowadays, insulating building materials are developed from the valorization of agro-resources. They show high ecological and hygrothermal performance. Before making them available on the market, there is a need to classify them according to their decay resistance. This paper aims to propose a test method that qualifies bio-based composites with respect to their performance. An accelerated aging test was carried out on 5 composites made with two different agro-resources (hemp and rape) and with different binders. It consists of exposing the specimens to $\left(30{ }^{\circ} \mathrm{C} ; 90 \% \mathrm{RH}\right)$ for three months. During the test, the specimens are regularly weighed and photographed. The sample mass and the percentage of surface contaminated by fungi are measured along the test. Finally, a microscopic view allows identifying the species of the developed molds.

\section{Keywords}

A. Biocomposite; B. Environmental degradation; D. Non-destructive testing; D. Optical microscopy; 


\section{Introduction}

The development of new insulating building materials from agro-resources of local agriculture (hemp shiv, flax shiv, wheat straw, etc.) is currently booming. The main quality of these materials is their hygrothermal performance when compared with traditional building materials. However, before they can be made available in the market, others characteristics need to be evaluated such as mechanical performance and durability. This paper investigates the decay resistance of the newly developed composites. Bio-based materials are assumed to be highly sensitive to the mold growth due to their chemical composition: cellulose, hemicellulose, lignin and proteins.

The molds are produced by wide variety of microorganisms, mainly microscopic fungi and yeasts. These play an important role in the decomposition of plant materials. These microorganisms grow and reproduce very quickly, spreading spores and mycelium.

These microorganisms may already be present inside building materials (walls, partitions, ceilings) or may be directly introduced into homes through ventilation. Their growth depends on various factors, in particular: flood, water leaks (roof or pipework), poorly-ventilated spaces (in kitchen, in bathroom)and building seals $[1,2]$. In all cases, the fungi will grow when materials contain free water. For wood, the water content at the fiber saturation point ranges from 20 to $30 \%$. The appearance of fungi induces a mass loss of between 5 and $10 \%$ and the mechanical properties decrease between 20 and $80 \%$ depending on the type of material [3]. The molds collect water, nutritional substances and minerals needed for their synthesis from the surrounding environment and the materials [2,4-7].

Although fungi are present in the atmosphere, higher concentrations may result in adverse health effects. Indeed, many fungal components are likely to cause adverse effects on the health of exposed individuals. Mycelial fragments can be present in ambient air and could be inhaled. Their walls contain glucans (complex sugar) with inflammatory properties. Spores may also cause allergic reactions such as allergic rhinitis or worsening of asthma symptoms. Furthermore, fungi release toxins of which toxicity may persist after the fungi have ceased to grow. The threshold of sensitivity varies from one individual to another, and according to the type of mold for each person. The individual response and the experienced symptoms vary considerably depending on the individual sensitivity and the duration of exposure to the fungi. Infants, children, the elderly, pregnant women and people suffering from 
respiratory diseases, allergies, asthma and weakened immune systems are usually more sensitive to mold exposure. Likewise, the severity is not necessarily proportional to the extent of exposure. Mold prevention and remediation in new and existing housing is thus not solely an aesthetic issue, but also one of public health and hygiene $[1,5,8,9]$.

There is therefore a need to classify materials depending on their decay resistance in order to use them appropriately. To qualify the durability of materials, different methods and standards exist such as: Johansson method [10], AWPA Standard E24-06 [11], ASTM 2012 [12] or BSI EN ISO 846 - 1997 [13], assessing the resistance of specimen surface to mold growth after fungi inoculation. For each of these methods, the intensity of specimen's mold growth is visually rated using a scale during the test period. Thus, this is a somewhat subjective type of assessment.

The aim of this paper is to develop a method to qualify bio-based composites with respect to their resistance to mold development. The composites were exposed over a three months period to unfavorable conditions: $30^{\circ} \mathrm{C}$ and $90 \% \mathrm{RH}$. These conditions are expected to initiate and accelerate mold growth on the surface of bio-based panels. The composite specimens were made with two different agro-resources (hemp and rape) mixed with different binders. They are tested without prior sterilization or inoculation with mold. Specimens are regularly weighed and photographed during the test. The evolution of two indicators is thus measured over time: the sample mass and the percentage of its surface contaminated by fungi. Two ways are used to rate the contaminated area: visual inspection as stated previously and digital image correlation (DIC). The latter method is developed in this work for quick quantification of the contaminated surface of the specimens by molds in an objective manner unlike the visual evaluation. At the end of the test, microscopic views are analyzed in order to identify the mold species which have contaminated the composite.

\section{Materials and methods}

\subsection{Bio-aggregates}

Two types of aggregates are considered in this study: hemp shiv and rape straw (Fig. 3). The main characteristics of these aggregates are reported in Table 1. The particle size distribution, bulk density and thermal conductivity were obtained using protocols set by RILEM TC 236-BBM [14]. The moisture 
buffer value (MBV) is measured for bulk materials according to a method based on the NORDTEST protocol [15].

The hemp shiv is a commercial product (Biofibat - CAVAC, France) commonly used to produce hemp concrete. The mean width of particles (W50) is $2.2 \mathrm{~mm}$ and the mean length (L50) is $8.0 \mathrm{~mm}$. The maximal width is $5.0 \mathrm{~mm}$ and the maximal length is $19.0 \mathrm{~mm}$. The thermal conductivity is 64.1 $\mathrm{mW} /(\mathrm{m} . \mathrm{K})$ for bulk density around of $110 \mathrm{~kg} / \mathrm{m}^{3}$. The $\mathrm{MBV}$ is $2.35 \mathrm{~g} /\left(\mathrm{m}^{2} . \% \mathrm{RH}\right)$. According the classification of the Nordtest project, bulk hemp shiv appears as an excellent hygric regulator (MBV higher than $\left.2 \mathrm{~g} /\left(\mathrm{m}^{2} . \% R H\right)\right)$.

The rape straw (supplied by CAVAC, France) is the residual portion of the threshing of rape commonly used for animal bedding, mulching or animal feeding. The mean width of particles is $3.1 \mathrm{~mm}$ and the mean length is $15.9 \mathrm{~mm}$. The maximal width is $8.5 \mathrm{~mm}$ and the maximal length is $45.2 \mathrm{~mm}$. The thermal conductivity is $49.9 \mathrm{~mW} /(\mathrm{m} . \mathrm{K})$ for bulk density around of $75 \mathrm{~kg} / \mathrm{m}^{3}$. The MBV is 2.25 $\mathrm{g} /\left(\mathrm{m}^{2} . \% \mathrm{RH}\right)$. According the classification of the Nordtest project, it is an excellent hygric regulator (MBV higher than $2 \mathrm{~g} /\left(\mathrm{m}^{2} . \% \mathrm{RH}\right)$ ).

Table 1 : Main characteristics of hemp shiv and rape straw

\begin{tabular}{lcc}
\hline \multicolumn{1}{c}{ Aggregates } & Hemp shiv & Rape straw \\
\hline Mean Width $(\mathrm{W} 50, \mathrm{~mm})$ & 2.2 & 3.1 \\
Maximal width $(\mathrm{mm})$ & 5.0 & 8.5 \\
Mean Length $(\mathrm{L} 50, \mathrm{~mm})$ & 8.0 & 15.9 \\
Maximal length $(\mathrm{mm})$ & 19.0 & 45.2 \\
Bulk density $\left(\mathrm{kg} / \mathrm{m}^{3}\right)$ & 107.9 & 73.3 \\
Thermal conductivity $(\mathrm{mW} /(\mathrm{m} . \mathrm{K}))$ & 64.1 & 49.9 \\
MBV $\left(\mathrm{g} /\left(\mathrm{m}^{2} . \% \mathrm{RH}\right)\right)$ & 2.35 & 2.25 \\
\hline
\end{tabular}

\subsection{Composite formulations}

The composite formulations are developed within ISOBIO project [16]. During this project, several lines of research are studied with the aim of producing, from these bio-aggregates and a green binder, a rigid insulation panel. The main lines of research are as follows:

- Use the adhesive properties of aggregates after treatment,

- Use crosslink binders to improve the mechanical properties and water repellence of composites, 
- Use a sol-gel treatment to improve the water repellence of composites.

Numerous formulations were investigated and the five best ones are selected to produce specimens for this study. They are made of rape straw or hemp shiv, treated or not, mixed with or without binders and with or without additives. The formulations are summarized in Table 2.

C1 composites are made of rape straw after exposure to alkali treatment. Preliminary work showed that after alkaline and thermal treatments on rape straw, the produced composites have good cohesion, which is induced by the polymerization of soluble components. This formulation has an advantage to only use treated rape straw and thus $100 \%$ bio-based insulation panels can be produced in the same line as the hemp-straw composites [17].

C2 composites are made of hemp shiv mixed with a binder formulated using a starch derivative and a crosslinker. The starch and its derivatives have good adhesive properties on the lignocellulosic substrates. However an important issue is the low energy chemical bonds (Van der Waals and hydrogen bonds), which ensure starch cohesion. Moreover, they can be easily hydrolyzed by water, resulting in poor water resistance of the composite. Therefore a crosslinker is added to create, after a thermal activation, covalent bonds between the starch macromolecules chains and thus, to form a three-dimensional network in order to improve the mechanical strength and the water resistance of the composite. C3 composites are made using the same formulation as $\mathrm{C} 2$ composites, but $2 \%$ of paraffin is added, to improve its water repellence.

C4 composites are made of hemp shiv coated with a sol-gel treatment to improve their water repellence. For the preparation of the sol-gel, $1 \mathrm{M}$ of TEOS was added to a mixture of $4 \mathrm{M}$ distilled water, $4 \mathrm{M}$ of absolute ethanol and $0.005 \mathrm{M}$ of nitric acid. $0.015 \mathrm{M}$ of HDTMS was added to the above mixture as the hydrophobic agent. The sol was vigorously stirred at $40^{\circ} \mathrm{C}$ and atmospheric pressure for nearly 2 hours. The sols were allowed to age for 96 hours in closed container at room temperature before to be mixed with the hemp shiv in order to coat them. In the case of $\mathrm{C} 4$ composites, this sol-gel 

binder improves the mechanical properties.

Table 2 : Specimens composition

\begin{tabular}{|c|c|c|c|c|c|}
\hline Formulations & C1 & $\overline{\mathrm{C} 2}$ & $\overline{C 3}$ & C4 & $\overline{C 5}$ \\
\hline Aggregates & $\begin{array}{c}\text { Rape straw } \\
100 \%\end{array}$ & $\begin{array}{c}\text { Hemp shiv } \\
90 \%\end{array}$ & $\begin{array}{c}\text { Hemp shiv } \\
88 \%\end{array}$ & $\begin{array}{c}\text { Hemp shiv } \\
100 \%\end{array}$ & $\begin{array}{c}\text { Hemp shiv } \\
90 \%\end{array}$ \\
\hline Treatment & Alkali & Without & Without & Sol-gel & Sol-gel \\
\hline Binder & Without & $\begin{array}{c}8 \% \text { Starch } \\
\text { derivative } \\
2 \% \text { Crosslinker }\end{array}$ & $\begin{array}{c}8 \% \text { Starch } \\
\text { derivative } \\
2 \% \text { Crosslinker }\end{array}$ & Witho & $\begin{array}{l}8 \% \text { Starch } \\
\text { derivative } \\
\% \text { Crosslinker }\end{array}$ \\
\hline Additive & Without & Without & $\begin{array}{c}\text { Paraffin } \\
2 \%\end{array}$ & Without & Without \\
\hline Solvent & Without & $\begin{array}{c}\text { Water } \\
33 \% \text { of dry } \\
\text { content }\end{array}$ & $\begin{array}{c}\text { Water } \\
33 \% \text { of dry } \\
\text { content }\end{array}$ & Without & $\begin{array}{c}\text { Water } \\
33 \% \text { of dry } \\
\text { content }\end{array}$ \\
\hline
\end{tabular}

\subsection{Composite production process}

For preparation of $\mathrm{C} 1, \mathrm{C} 2, \mathrm{C} 3$ and $\mathrm{C} 5$ composites, the bio-aggregates (treated, coated or not) are moistened with the solvent and/or the binder, if any. Three specimens are produced from the same mixture. This batch is divided into three equal parts (A, B and C) and each part is introduced in one of the three cells of a mold. Each part is compacted 5 times at $0.25 \mathrm{MPa}$ in the mold and then placed in an oven at $190{ }^{\circ} \mathrm{C}$ for 2 hours. The three specimens of dimensions $100 \times 100 \times 50 \mathrm{~mm}^{3}$ are demolded once they cool down to room temperature (Figure 1).

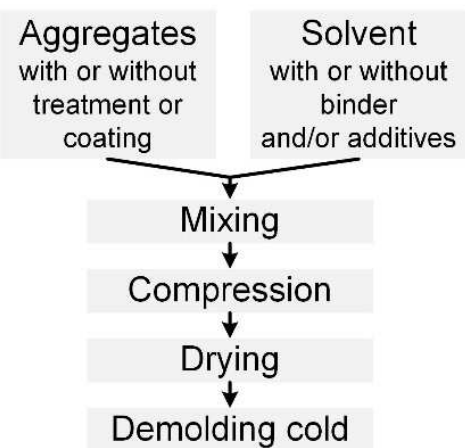

Figure 1 : Flow-chart of composites production (except C4 formulation)

For C4 formulation, mixing of the constituent materials, hemp shiv ( 75 vol\%) and sol ( 25 vol\%), were carried out manually to achieve a uniform mixture. The mass of the materials was pre-calculated to target a final density of $175 \mathrm{~kg} / \mathrm{m}^{3}$ for the composites. Hemp shiv were mixed with the sol and then placed into a phenolic ply mold, tamped down and left for overnight in the oven at $80{ }^{\circ} \mathrm{C}$. The 
163

164

165

166

167

168

169

170

171

172

173

174

175

176

177

178

179

180

181

182

183

184

185

186

187

specimens of dimensions $100 \times 100 \times 50 \mathrm{~mm}^{3}$ were removed from the molds and transferred to a conditioning room at $19^{\circ} \mathrm{C}$ and $50 \% \mathrm{RH}$.

Figure 2 shows the produced composites and Table 3 gives their apparent density. The composites based on hemp shiv have very close densities ranging from 173 to $203 \mathrm{~kg} / \mathrm{m}^{3}$. The composite based on rape straw (C1) has the highest density $\left(288 \mathrm{~kg} / \mathrm{m}^{3}\right)$ due to much higher density of the aggregate after alkali-treatment which reduces intra and inter-particle porosity. The $\mathrm{C} 1$ composites have the highest $\mathrm{pH}$ (10) due to alkali treatment. The composites made with starch derivative based binder and crosslinker (C2, $\mathrm{C} 3$ and $\mathrm{C} 5)$, have an acid $\mathrm{pH}$ of 6 . The composites which are glued with sol-gel (C4), have the lowest $\mathrm{pH}(4)$.

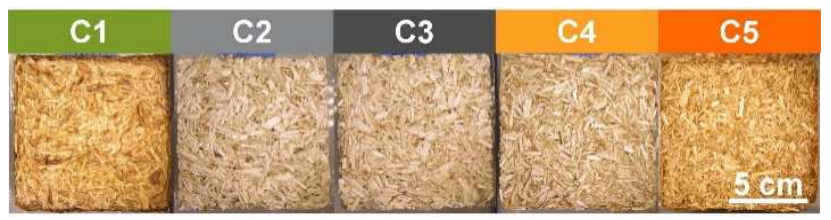

Figure 2 : Developed composites

Table 3 : Apparent density and $\mathrm{pH}$ surface of composites

\begin{tabular}{cccccc}
\hline $\mathbf{N}^{\circ}$ & $\mathbf{C 1}$ & $\mathbf{C 2}$ & $\mathbf{C 3}$ & $\mathbf{C 4}$ & $\mathbf{C 5}$ \\
\hline Density & 287.66 & 181.02 & 184.21 & 173.92 & 203.10 \\
$\left(\mathrm{~kg} / \mathrm{m}^{3}\right)$ & \pm 9.49 & \pm 2.82 & \pm 1.51 & \pm 6.11 & \pm 4.20 \\
$\mathrm{CoV}$ & $3.30 \%$ & $1.56 \%$ & $0.82 \%$ & $3.51 \%$ & $2.07 \%$ \\
$\mathrm{pH}$ & 10 & 6 & 6 & 4 & 6 \\
\hline
\end{tabular}

\subsection{Methods for characterization}

\subsubsection{Biological aging}

The accelerated aging test evaluates the fungal resistance of the composites at given temperature and humidity and is schematized in Figure 3. After stabilization at $23^{\circ} \mathrm{C}$ and $50 \% \mathrm{RH}$, the biological aging tests are performed in a climate chamber (Vötsch VC0034, Figure 3.1) under controlled temperature and relative humidity at $30^{\circ} \mathrm{C}$ and $90 \% \mathrm{RH}$ for three months. The specimens are tested without prior sterilization or inoculation with mold to closely reproduce a real exposure situation. 
For each formulation, three specimens are tested. Each specimen (3 specimens per formulation) is placed in a plastic box to prevent contamination between specimens. In order to facilitate image treatment, the specimen is prevented from moving in the box, by making use of the aluminum adhesive block. Furthermore, the experimental bench allows to take pictures of the top surface of the specimens in a consistent manner (Figure 3.3). Every week day, the specimens are weighed (Figure 3.2) and visually inspected. Pictures are captured with a camera (Coolpix 8700, 8 Megapixels, Nikon).

For the analysis, mass variation from the steady state point is related to the exchange surface area (including horizontal top and lateral surfaces of the specimen). The mass loss of each formulation is expressed as the mass ratio between the maximal mass and this of the given time, using Equation (1).

$M L=\frac{m_{\max }-m}{m_{\max }} \times 100$

Where $\mathrm{ML}$ is the mass loss $(\%) ; \mathrm{m}_{\max }$ is the maximal mass of composite $(\mathrm{g})$ and $\mathrm{m}$ is the mass of composite at the given time $(\mathrm{g})$.

On the final day of the test, the samples are visually evaluated for mold growth according the rating scale of BSI EN ISO 846 - 1997 [13], which is shown in Table 4. This method is subjective. Thus, the final rating is the average value of the given rating by each author in this publication, making a total of 8 people.

Table 4: Assessment of growth following the BSI EN ISO 846 - 1997 [13]

\begin{tabular}{cl}
\hline Intensity of growth & Evaluation \\
\hline 0 & No growth apparent under the microscope. \\
1 & No growth visible to the naked eye, but clearly visible under the microscope. \\
2 & Growth visible to the naked eye, covering up to $25 \%$ of the test surface. \\
3 & Growth visible to the naked eye, covering up to $50 \%$ of the test surface. \\
4 & Considerable growth, covering more than $50 \%$ of the test surface. \\
5 & Heavy growth, covering more than $75 \%$ of the test surface. \\
\hline
\end{tabular}

209 The chosen method has an advantage of being non-intrusive unlike other methods found in the 210 literature: 
- Use of adhesive to remove fungal spores from the substrate and then scanning of mold imprint [18];

- Scanning two sides of the specimen [19].

214 It should be noted that during the entire period of the test the biotope remains undisturbed.

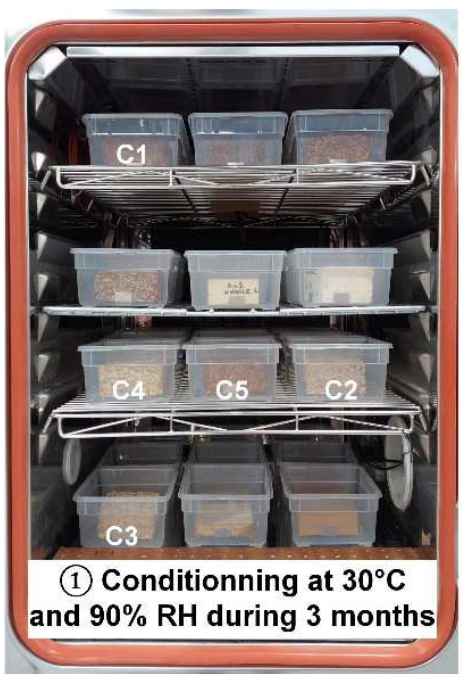

(3) Experimental bench for photo recording

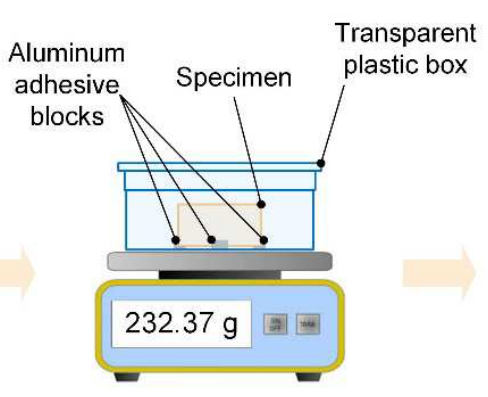

(2) Weighing once a day (excluding weekends)
217

218

Figure 3: Experimental device for biological aging: conditioning, weighing and photo recording

\subsubsection{Image analysis}

In this study, the chosen contamination indicator is the relative photographed surface contaminated by mold with reference to the total surface. A similar approach is used by various researchers in the field such as Nielsen et al [2], Johansson et al [10], Clausen and Yang [18] and Garzon-Barrero et al [19]. To evaluate the mold growth between two dates $t_{0}$ and $t$, two photographs of the same specimen have been taken. In this study, a very simple experimental device has been chosen (Figure 3, Experimental bench for photo recording) to avoid use of sophisticated equipment. However for image analysis, it is necessary to use or to develop specific IT-tools.

The image analysis is performed in two steps:

- Firstly, the displacement field between images recorded at $t_{0}$ and $t$ is computed. This displacement may be due to operator handling (such as accidental motion of the specimen or the camera) or caused by a dilatation of the composite due to swelling induced by moisture change. This step is achieved, thanks to Digital Image Correlation (DIC) analysis, using the code DIGIMCO developed by Marc François in MATLAB software and freely available. Similar 


\section{ACCEPTED MANUSCRIPT}

tools, whether free or commercial software exist $[20,21]$ and have been used for several years to perform displacement field measurement, or to evaluate mechanical properties [22-24].

- Secondly, the location of mold is revealed thanks to the error map of correlation between images recorded at time $t_{0}$ and $t$. It represents the discrepancy between the two images once correlated in space. A gray level difference reveals the presence of molds.

A digital image is a set of data produced by recording variation in the intensity of a signal. It's a matrix of $r$ rows and $c$ columns. Each pixel has a value that represents the brightness of a given color at any specific location. In this paper, the image $f$ and the image $g$ designate the images of an object recorded in the initial state (at time $t_{0}$ ) and in the final state (at time $t$ ) respectively. The discrete functions $f(\boldsymbol{X})$ and $g(\boldsymbol{X})$ denote the gray levels associated with pixel of the image $\mathrm{f}$ and $\mathrm{g}$ respectively, located at position $\boldsymbol{X}$ (the coordinates are in pixels). The location of a given texture point is referred to be as $\boldsymbol{X}$ in image f and $\boldsymbol{x}$ in image $\mathrm{g}$ (see Figure 4). Possible transformations between two images are schematized in Figure 4 (i.e. dilatation, translation and rotation). The first step of the analysis is to compute the displacement field $\mathbf{u}(\mathbf{X})$ which gives the best fit between images $f$ and $g$. The texture of the two images is quite similar and is used to determine this fit.

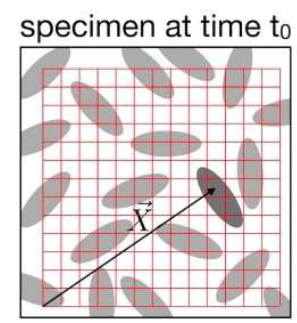

Image $f$

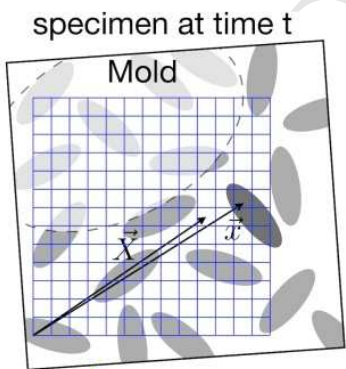

Image $g$

Figure 4: Digital image correlation between initial image $f\left(\right.$ time $t_{0}$ ) and current image $g$ (time $t$ )

The displacement $\mathbf{u}$ is defined by:

$$
\mathbf{x}=\mathbf{X}+\mathbf{u}
$$

Supposing a homogeneous deformation, the mapping of the transformation is a parameterized field of the form:

$\mathbf{X}=\mathbf{F} .(\mathbf{X}+\mathbf{T})$

where $\boldsymbol{T}$ is a translation vector described by the parameters $\lambda_{1}$ and $\lambda_{2}$.

$\lambda_{1}=T_{1}$

$$
\lambda_{2}=T_{2}
$$


and $\boldsymbol{F}$ is the deformation gradient tensor described by the parameters $\left(\lambda_{3}, \lambda_{4}, \lambda_{5}, \lambda_{6}\right)$ :

$\lambda_{3}=n\left(F_{11}-1\right)$

$\lambda_{4}=n\left(F_{12}\right)$

$\lambda_{5}=n\left(F_{21}\right)$

$\lambda_{6}=n\left(F_{22}-1\right)$

265

266

267

268

269

270

271

272

273

274

275

276

277

278

279

280

281

282

283

where $n$ is a weighting factor. It must be emphasized that the tensor $\mathbf{F}$ includes pure deformation, rigid rotation and dilatation. The DIC method [22] is based on an assumption of optical flow conservation between images $\mathrm{f}$ and $\mathrm{g}$ whose texture does not significantly differ thus $f(\boldsymbol{X})=g(\boldsymbol{x})=g(\boldsymbol{X}+\boldsymbol{u})$ (with a possible error). The experimental conditions are compatible with these assumptions since the brightness of the images and the color of the composites do not significantly evolve during the test. To find the displacement $\boldsymbol{u}$ or the parameters $\lambda_{i}$, the sum of squared differences $\varphi$ of the gray levels have to be minimized over the zone of interest $-Z_{i^{-}}$which corresponds in this study to the whole photographed face of the composite is:

$\varphi\left(\lambda_{1}, \lambda_{2}, \lambda_{3}, \lambda_{4}, \lambda_{5}, \lambda_{6}\right)=\sum_{X \in Z_{i}}(g(\boldsymbol{x})-f(\boldsymbol{X}))^{2}$

However the computation of the displacement field $\boldsymbol{u}$ is not the objective of this study. It is only necessary to compare images $f$ (original) and $g$ (with mold), pixel to pixel, at exactly the same location. Here, the presence of mold changes the gray level. The zones affected by mold are supposed to be large with respect to the texture size of the image of the composite. Then, assuming a uniform variation of the gray level $b$, (due to the presence of mold) the equation 10 becomes:

$\varphi\left(\lambda_{1}, \lambda_{2}, \lambda_{3}, \lambda_{4}, \lambda_{5}, \lambda_{6}\right)=\sum_{X \in Z_{i}}(g(\boldsymbol{x})+b-f(\boldsymbol{X}))^{2}$

The result of the minimization (i.e. the computation of parameters $\lambda_{i}$ or the displacement field $\boldsymbol{u}$ ) is not modified by the presence of $\mathrm{b}$ since it does not modify the gradient of $\varphi$ [22]. Figure 5 illustrates the method. The function $f(\boldsymbol{X})$ represents a 1D example of gray level in the initial image $\mathrm{f}$ (without mold). The function $g(\boldsymbol{X})$ represents the final grey level of image $g$ in which molds have changed the gray level of some domains. A rigid body motion is visible. Once computed the best correlation (Equation 11) the maximum and minimum shall match between $f(\boldsymbol{X})$ and $g(\boldsymbol{x})$. Then, the difference $g(\boldsymbol{x})-f(\boldsymbol{X})$ exhibits the location of the colonization. 

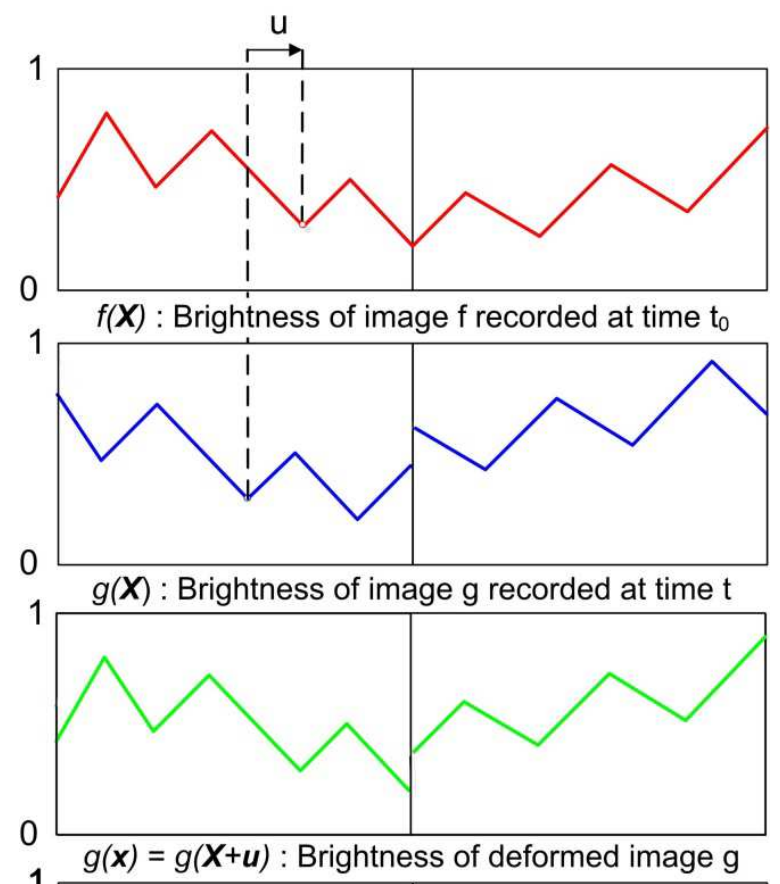

Figure 5: Relative brightness, of image $g$ and $f$ : an error involves the detection of a new object.

As an example, a test was performed on an 8-bit image (brightness coded from 0 to 256) of the composite (C1) without visible mold (see Figure 6). The reference image 6.a is compared with the image (6.b). It is a photography of the same composite taken 24 hours later also free of molds. In image 6.c an inscription is added with drawing software. Then, with DIGIMCO, the uniform displacement field which allows to superimpose the images 6.a and 6.b first, and then the images 6.a and 6.c are searched. Once the displacement field has been obtained, the map of the correlation errors between 6.a and 6.b is displayed on the image 6.d. On the image 6.e the map of the correlation errors between 6.a and 6.c is also displayed. On the error map 6.e, the inscription added to the image 6.c is clearly visible while the error map $6 . d$ is uniform and has virtually zero errors. From this error map, a thresholding operation (binarization) makes it possible to isolate the change, in this example, the inscription "Test DIGIMCO". 


\section{ACCEPTED MANUSCRIPT}

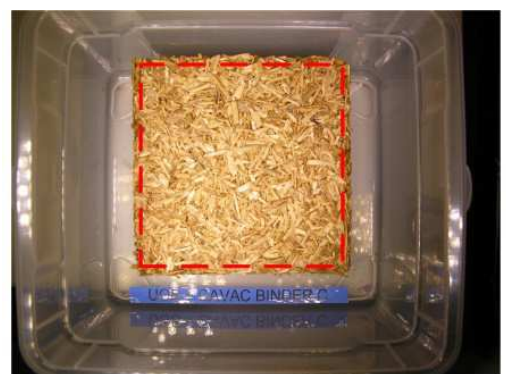

a) Original photography at time $t_{0}$

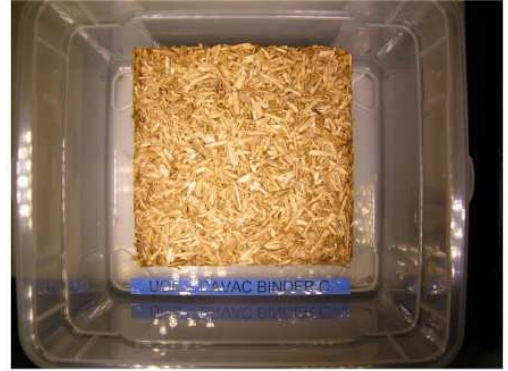

b) Photography at time $t$

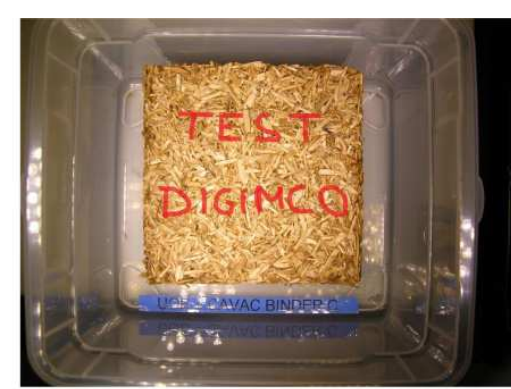

c) Modified photography at time $t$
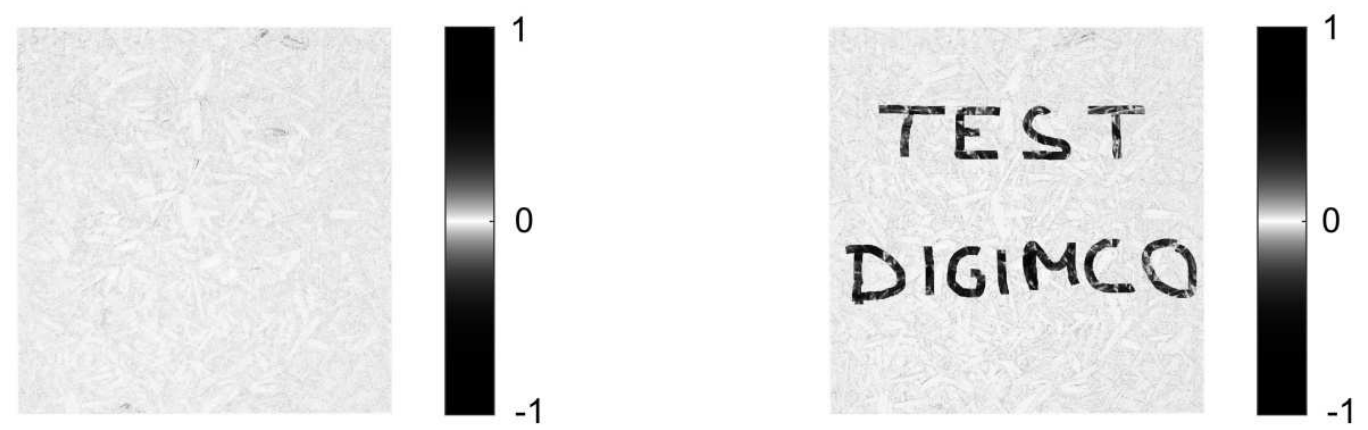

d) Correlation error between images a \& b

e) Correlation error between images a \& c

Figure 6: Example of object detection using DIC

305

306

307

308

309

310

311

312

313

It should be emphasized that in the traditional use of the DIC method, the surface of the studied object is covered with a randomly painted speckle pattern. This surface preparation allows to obtain a highly contrasted and unstructured image. This is not the case for this test. The surface of the composite acts as the randomly speckle pattern. The presence of hundreds of particles entangled without a regular pattern on the visible surface of the composite makes it possible to apply the DIC method without modifications. Thus, using the DIC does not require any treatment or modification of the environment likely to modify the growth of the studied organism. 


\section{ACCEPTED MANUSCRIPT}

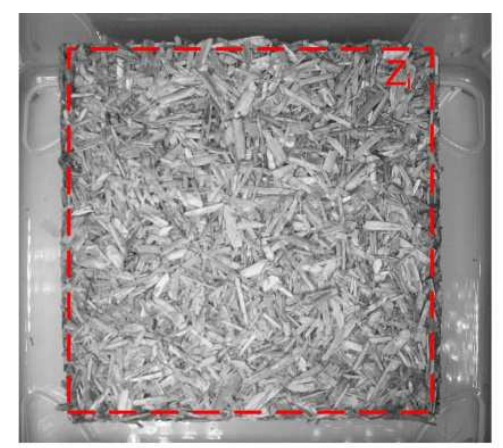

a) Original image at time $t_{0}$

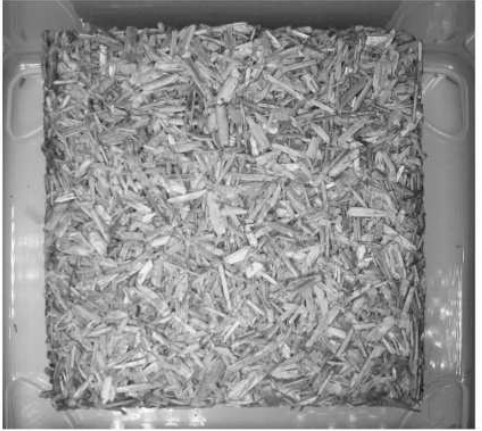

b) Image at time $t=t_{0}+2$ days

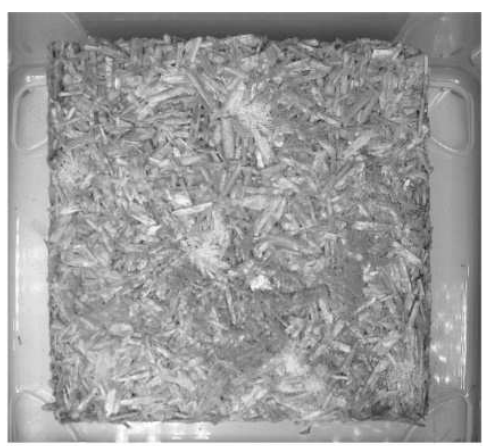

c) Image at time $t=t_{0}+16$ days

Step I :DIC

Step II : threshold

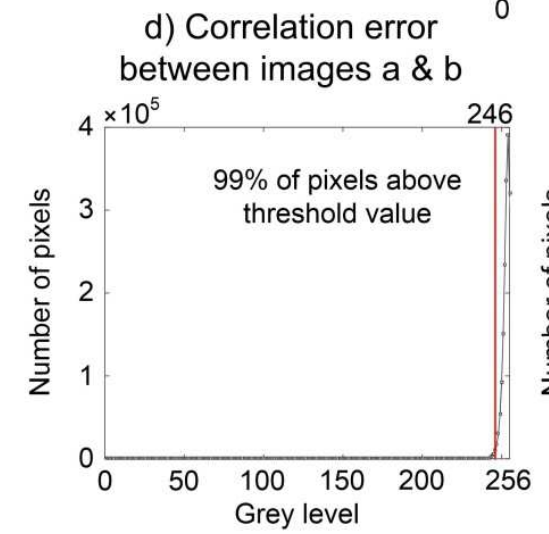

f) Distribution of grey level in image $d$

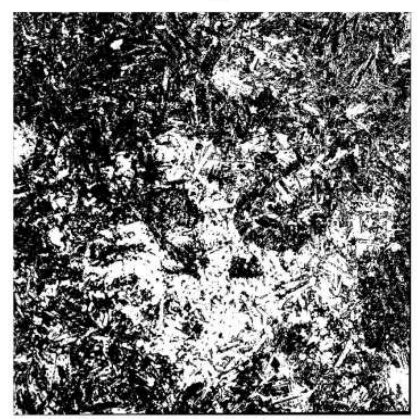

h) Image $g$ after thresholding
255

255
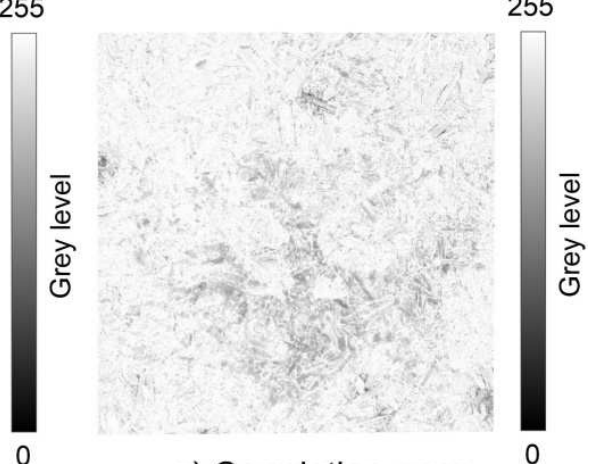

e) Correlation error

between images a \& $\mathrm{C}$

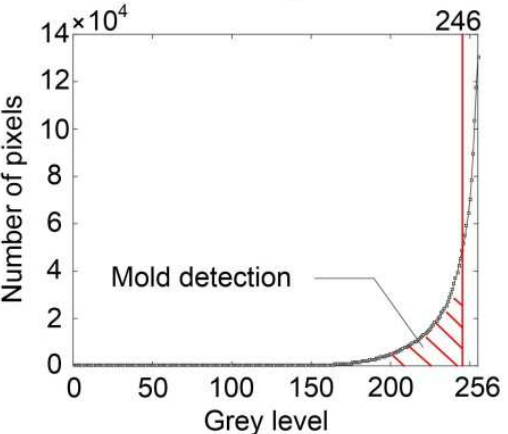

g) Distribution of grey level in image $e$

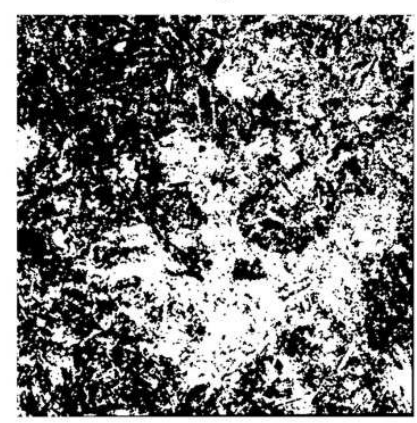

i) Image $\mathrm{h}$ after noise treatment : mold detection

Figure 7: Procedure of image analysis, DIC and post-treatment applied on composite C5

317 Once correlation error maps are calculated for each image, the post-processing operation is 318 performed with MATLAB. The entire image processing procedure is summarized in Figure 7 . It 
requires at least 3 pictures: the initial image of the composite 7.a, an image without apparent molds b) and the image to be analyzed 7.c. After obtaining correlation maps 7.d and 7.e, a thresholding is performed. The choice of the threshold value is by definition arbitrary. However, the study of the correlation errors map obtained for an image supposed without fungi (see a sample at $t=t_{0}+2$ days on Figure 7.d) allows to propose a coherent and systematic threshold value. On this example, $99 \%$ of the pixels have a gray level greater than 246 (see Figure 7.f). This value was used for the thresholding operations performed on the photographs taken the following days.

Pixels which value is below this threshold value are considered to be contaminated (see Figure 7.g). After the thresholding, the Figure 7.h is obtained). A morphological operation of opening and closing of the black-and-white image is then performed to filter the isolated pixels (with the "imopen" and "imclose" function of MATLAB) and reduce apparent measurement noise. Finally, the number of white pixels and black pixels in the image are counted to get the percentage of surface contaminated by fungi.

\subsubsection{Microscope visualizations}

After the three-month test period, microscope visualizations are performed in this study to identify the type of mold which are developed on the contaminated composite surface. The infected shiv are collected with a pair of tweezers and are observed under a microscope LCD (5 Megapixels, Bresser). Pictures are captured at $50 \mathrm{x}$ and $125 \mathrm{x}$ magnification. Then, the pictures are opened with Image $\mathrm{J}$ $(\mathrm{NIH})$ with the addition of the Microscope Measurement Tools plugin (Fij) to take measures and scale bar is added. The microscope is calibrated for a $50 x$ and a $125 x$ magnification using an optical fiber to $125 \pm 0.7 \mu \mathrm{m}$ in diameter (Corning ${ }^{\circledR}$ SMF-28® Ultra Optical Fiber). The determined scale is the average value of five measurements and is validated using a coated optical fiber to $242 \pm 5.0 \mu \mathrm{m}$ in diameter (Corning® SMF-28® Ultra Optical Fiber).

\section{Results and Discussions}

\subsection{Macroscopic visualizations}

Figure 8 gives the pictures of the $\mathrm{C} 1$ to $\mathrm{C} 5$ specimens at several times during the test period. The visual inspection shows that during this test, $\mathrm{C} 1$ composite does not show any fungal development. 


\section{ACCEPTED MANUSCRIPT}

349

350

351

352

353

354
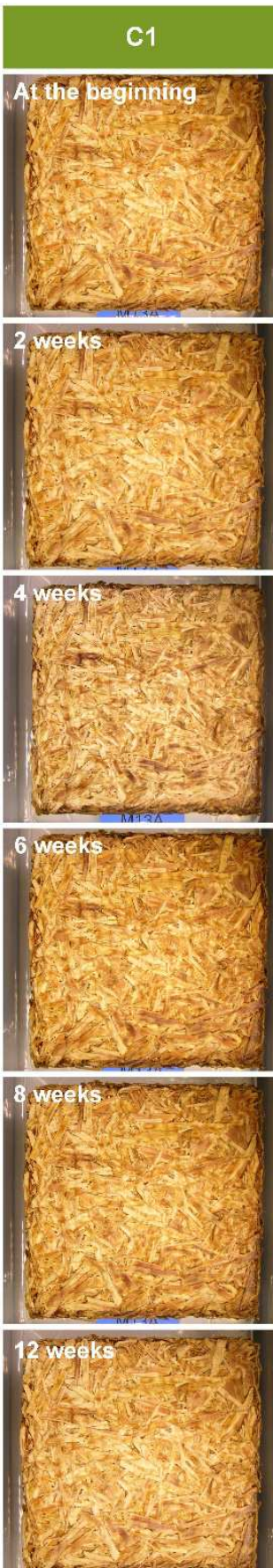

Figure 8: Specimens on the weeks 0,2, 4, 6, 8 and 12 of ageing test
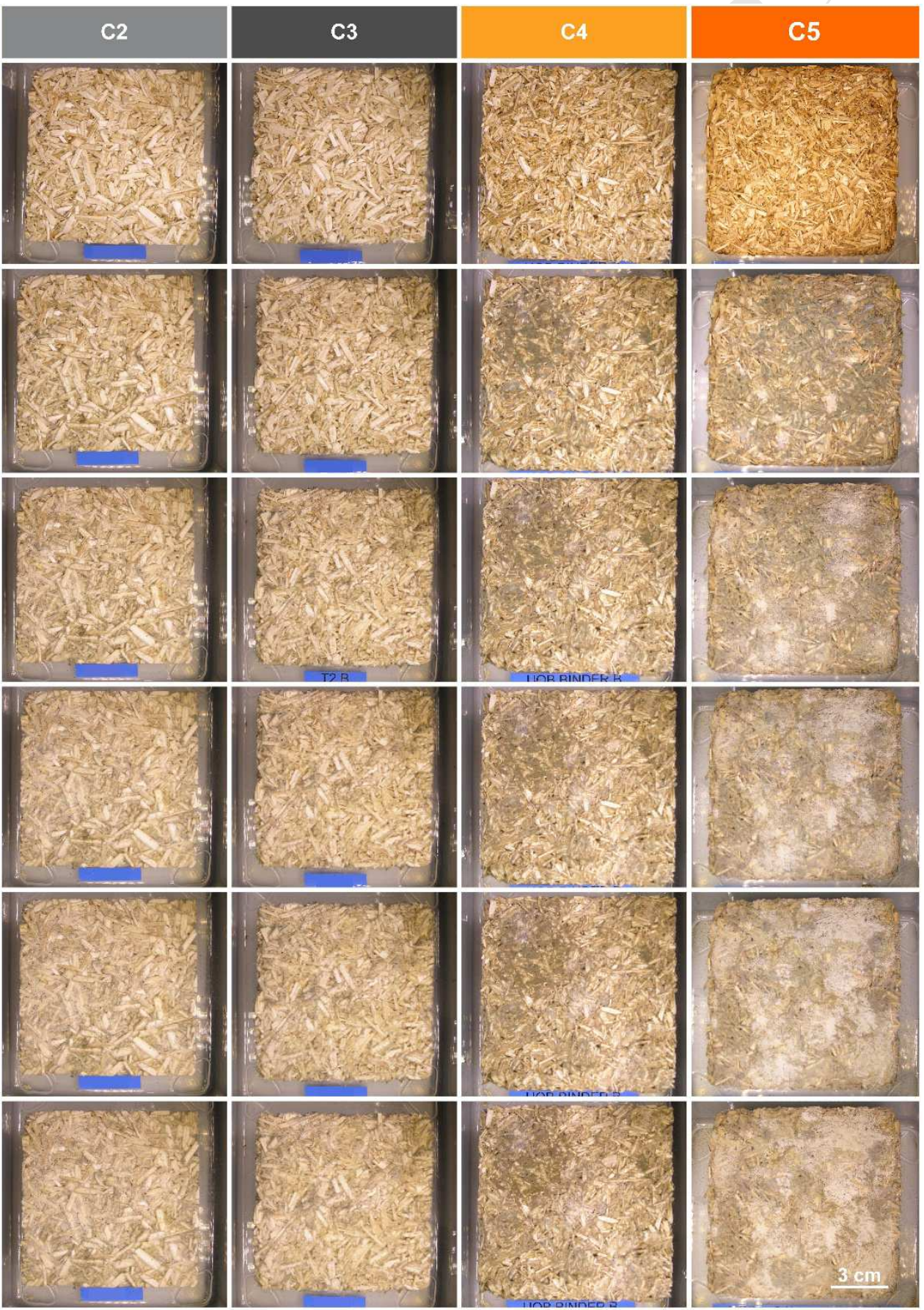
Figure 9 gives the average ratings of the visual evaluation given by the authors with the rating scale of BSI EN ISO 846 - 1997 [13] at the end of test. C1 composite does not have visible fungi. C3 composite has less than $25 \%$ of its surface contaminated. C2 and C4 composites have between 25 and $50 \%$ of their surface contaminated, with C4 being probably the more contaminated of the two.

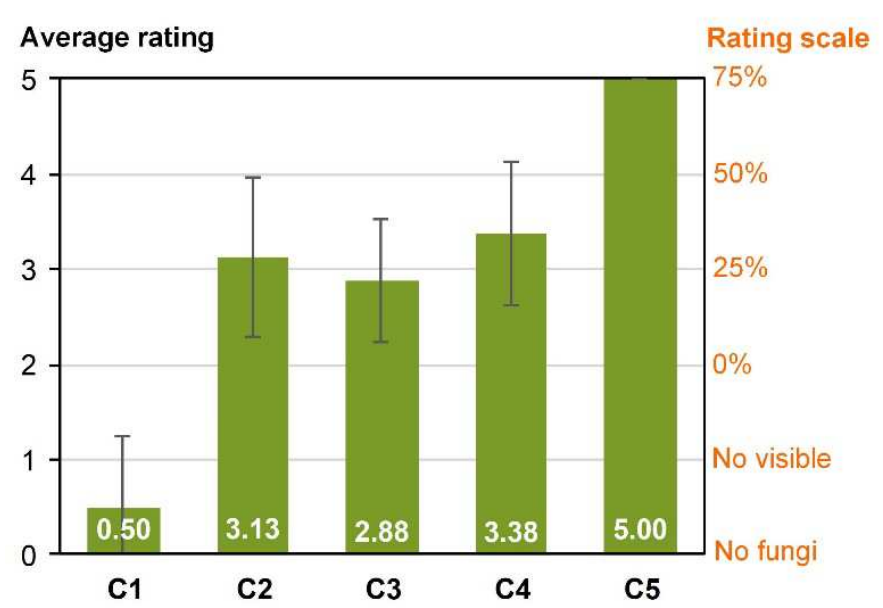

Figure 9: Average rating of mold growth on specimens with the rating scale of BSI EN ISO $846-1997$ (British

\subsection{Mass loss}

Figure 10 gives the mass variation at $30^{\circ} \mathrm{C}$ and $90 \% \mathrm{RH}$ from the steady state point $\left(23^{\circ} \mathrm{C}\right.$ and $50 \%$ $\mathrm{RH}$ ), related to the exchange surface area (including top and lateral surfaces of specimens). During the first week of exposure, all specimens show an increase in mass due to water vapor adsorption resulting in a water content of about $20 \%$ in specimens. From the eighth day, C5 composite slightly decreases in mass. From the ninth day, $\mathrm{C} 2, \mathrm{C} 3$ and C4 composites slightly decrease in mass too. The mass loss is due to the fungi development. C5 composite has the highest mass loss and C3 composites has the lowest mass loss. The two others composites have similar mass loss.in contrast, from the eighteenth day, $\mathrm{C} 1$ formulation slowly increases in mass before stabilizing and reaching water content of about $54 \%$ at the end of the test. 


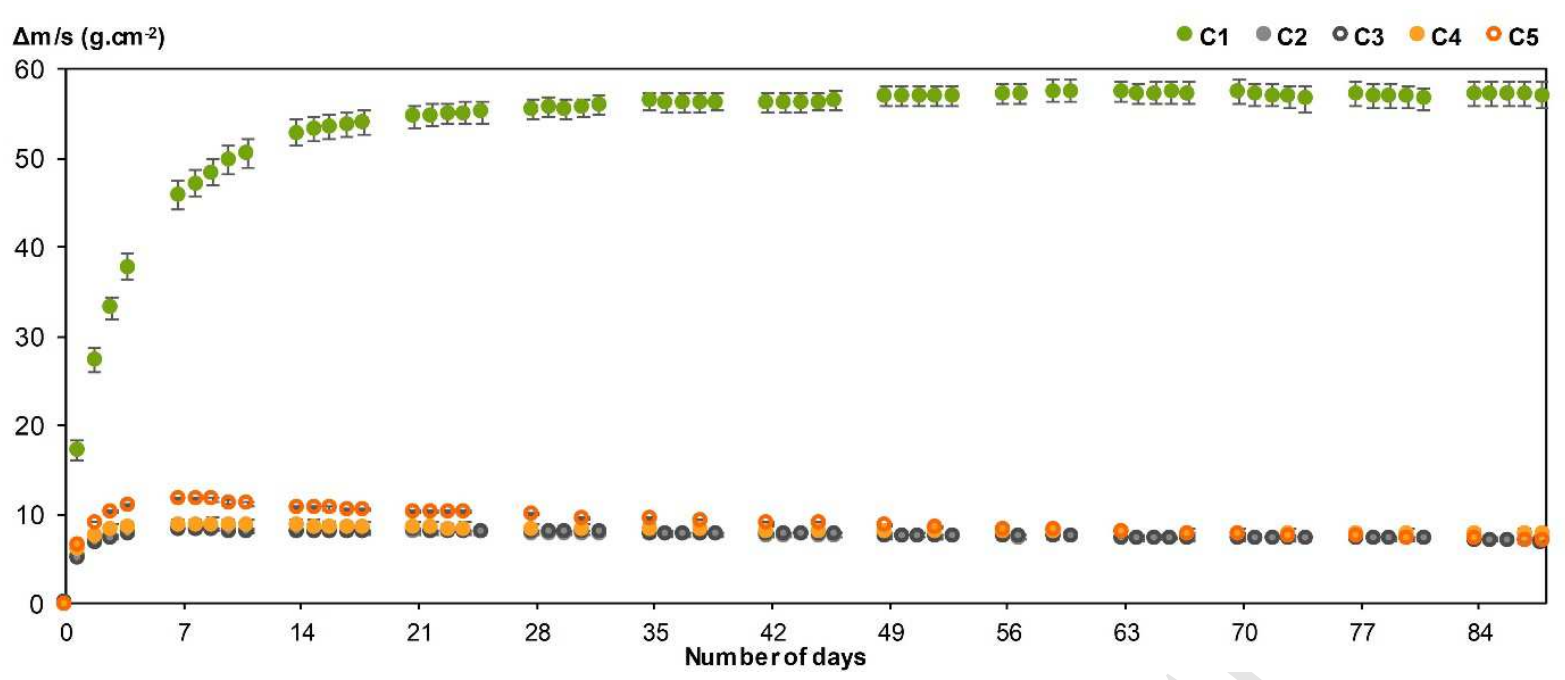

Figure 10: Variation of mass $\left(\right.$ at $\left.30^{\circ} \mathrm{C}, 90 \% \mathrm{RH}\right)$ from the steady state point at $\left(23^{\circ} \mathrm{C}, 50 \% R H\right)$, related to the exchange surface area

Figure 11 and Table 5 give the mass loss for C2, C3, C4 and C5 composites during the test. The kinetics of mass loss increase linearly for the four formulations after the first week. This week certainly corresponds to the time needed to reach a water content threshold in the specimens in order to trigger mold growth. The correlation coefficients of the fitting curves are good as they are higher than 0.93 . C5 composite has the highest mass loss. C3 composite has the lowest mass loss. This is probably due to the addition of paraffin which increases the water repellence. Moreover, the amount of adsorbed water by the C3 composite is lower than other composites. C2 and C4 composites have almost similar mass loss, thus the sol-gel coating does not have an impact on the kinetics of water vapor absorption. At the end of the test, these three formulations have a mass loss about $1.15 \%$ whereas the C5 composite has the highest mass loss (4.28\%).

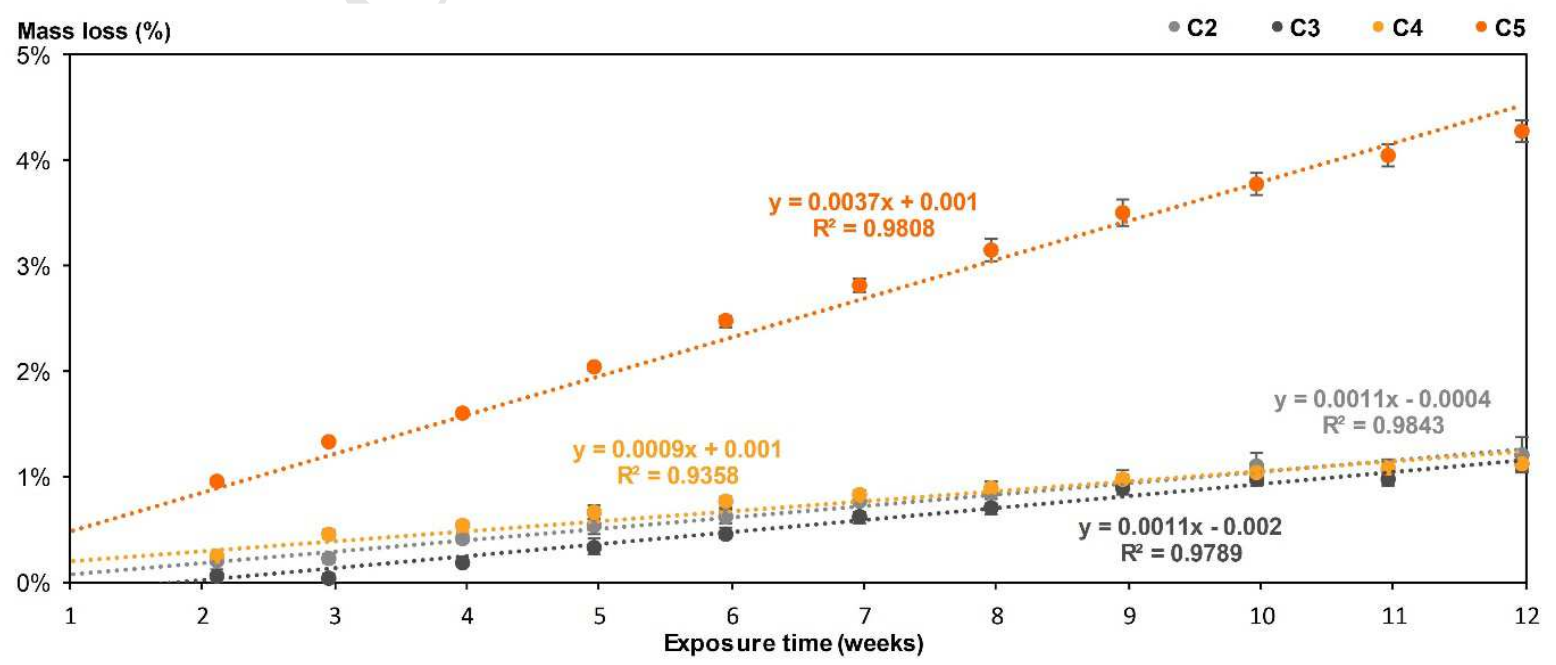




\section{ACCEPTED MANUSCRIPT}

Figure 11: Mass loss for the tested composites during the ageing test

Table 5: Mass loss (ML, \%) for the tested composites according to the exposure time (weeks)

\begin{tabular}{lcccc}
\hline Time (weeks) & ML C2 & ML C3 & ML C4 & ML C5 \\
\hline $\mathbf{0 . 9 6}$ & $0.00 \pm 0.00 \%$ & $0.00 \pm 0.00 \%$ & $0.00 \pm 0.00 \%$ & $0.00 \pm 0.00 \%$ \\
$\mathbf{2 . 1 1}$ & $0.21 \pm 0.02 \%$ & $0.06 \pm 0.06 \%$ & $0.23 \pm 0.02 \%$ & $0.94 \pm 0.01 \%$ \\
$\mathbf{2 . 9 6}$ & $0.23 \pm 0.04 \%$ & $0.03 \pm 0.04 \%$ & $0.45 \pm 0.04 \%$ & $1.33 \pm 0.00 \%$ \\
$\mathbf{3 . 9 6}$ & $0.42 \pm 0.05 \%$ & $0.19 \pm 0.04 \%$ & $0.53 \pm 0.05 \%$ & $1.61 \pm 0.02 \%$ \\
$\mathbf{4 . 9 6}$ & $0.53 \pm 0.07 \%$ & $0.33 \pm 0.07 \%$ & $0.66 \pm 0.06 \%$ & $2.03 \pm 0.03 \%$ \\
$\mathbf{5 . 9 6}$ & $0.62 \pm 0.07 \%$ & $0.46 \pm 0.05 \%$ & $0.76 \pm 0.06 \%$ & $2.47 \pm 0.05 \%$ \\
$\mathbf{6 . 9 6}$ & $0.76 \pm 0.10 \%$ & $0.62 \pm 0.05 \%$ & $0.82 \pm 0.06 \%$ & $2.81 \pm 0.07 \%$ \\
$\mathbf{7 . 9 6}$ & $0.85 \pm 0.10 \%$ & $0.71 \pm 0.08 \%$ & $0.89 \pm 0.06 \%$ & $3.15 \pm 0.10 \%$ \\
$\mathbf{8 . 9 6}$ & $0.95 \pm 0.10 \%$ & $0.90 \pm 0.08 \%$ & $0.97 \pm 0.05 \%$ & $3.50 \pm 0.12 \%$ \\
$\mathbf{9 . 9 6}$ & $1.10 \pm 0.13 \%$ & $0.97 \pm 0.06 \%$ & $1.04 \pm 0.07 \%$ & $3.78 \pm 0.11 \%$ \\
$\mathbf{1 0 . 9 6}$ & $1.05 \pm 0.11 \%$ & $0.98 \pm 0.07 \%$ & $1.08 \pm 0.07 \%$ & $4.04 \pm 0.10 \%$ \\
$\mathbf{1 1 . 9 6}$ & $1.21 \pm 0.16 \%$ & $1.13 \pm 0.06 \%$ & $1.12 \pm 0.08 \%$ & $4.28 \pm 0.10 \%$ \\
\hline
\end{tabular}

\subsection{Image analysis}

401 Figure 12 shows some pictures taken at the end of the test which are used to get the percentage of
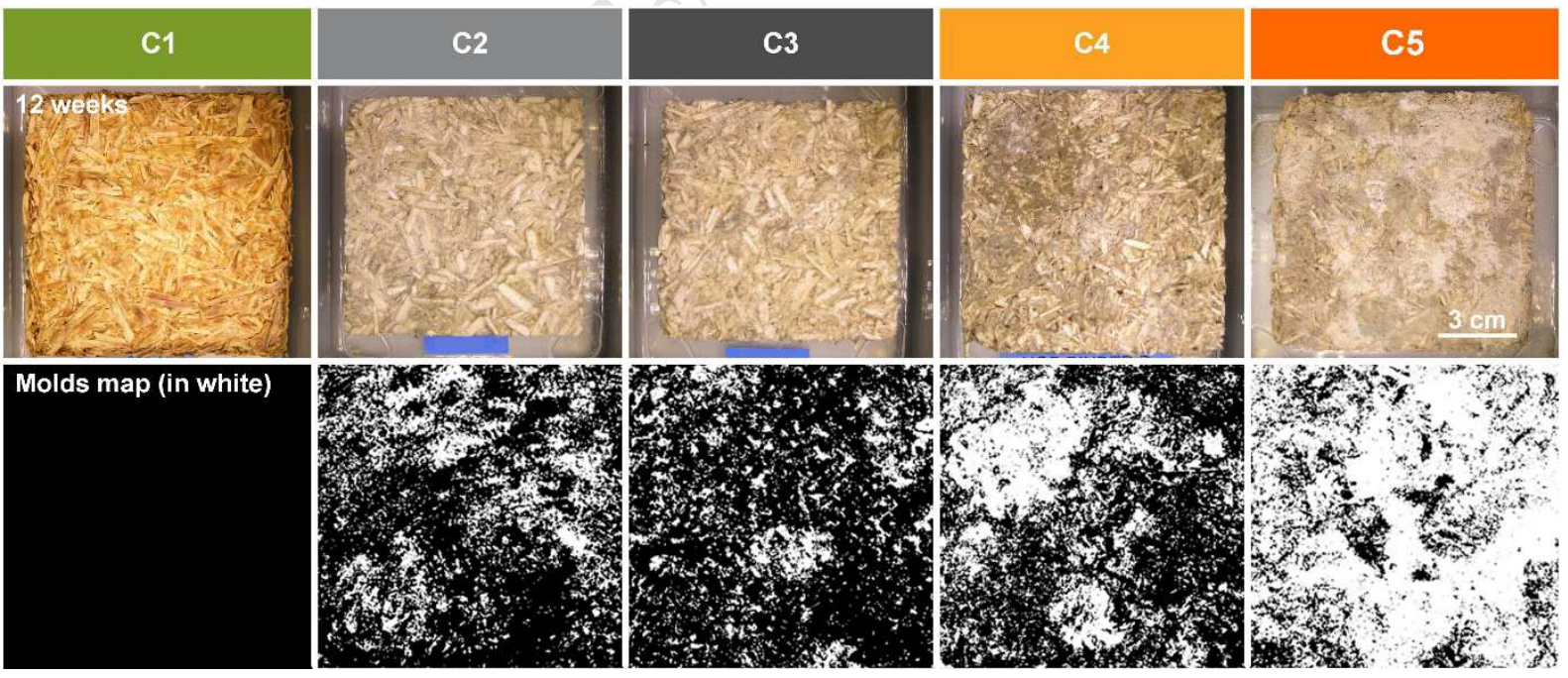

Figure 12 : Pictures before and after DIC treatment at the end of the test

The image analysis leads to the estimation of the surface ratio contaminated by the fungal growth during the test period at $30{ }^{\circ} \mathrm{C}$ and $90 \% \mathrm{RH}$ (Figure 13). The different mold growth rate between 
formulations are observed. Overall, C5 specimens have greater fungal growth with a higher standard deviation between the three specimens. C3 specimens have the slowest rate of growth over the 12 week test period. For all specimens, there is a substantial increase in growth during the second week which corresponds to the exponential phase of the fungal growth. During this period, the nutriments are in excess. Thus, the first week corresponds to the time required by the growth conditions to become favorable. The water content of specimens is around $10 \%$ at the beginning of the test. 1 week is required to double this value. This phase is called the lag phase. During the third week, the intensity of growth decreases. It corresponds to the slowdown phase. This is due to a depletion of the culture medium (composites) and an accumulation of waste. This phase goes on two weeks in the case of C5 composite. After the slowdown phase, the ratio of contaminated surface reaches a plateau until the end of the test. This means that the growth becomes zero and therefore the molds that grow multiply and replace those who die. This corresponds to the stationary maximum phase. At the end of test, the mean contaminated surface is $21.87 \%$ for C3 specimens, $28.36 \%$ for C2 specimens, 34.69 \% for C4 specimens and $77.50 \%$ for C5 specimens. Growth kinetics observed here are consistent with what is described in the biology literature [25]. These results suggest that the image analysis method provides consistent and exploitable results for this study.

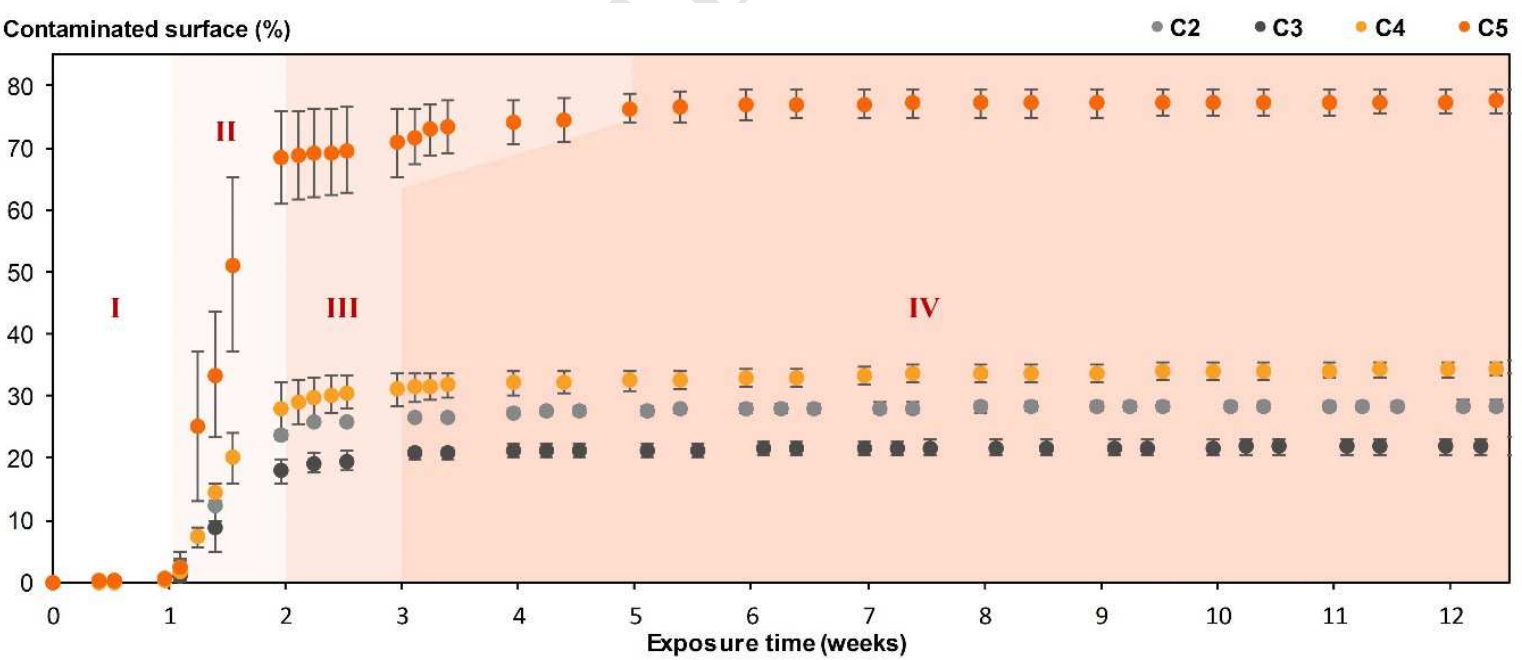

Figure 13: Image analysis: rating of the contaminated surface of C2, C3, C4 and C5 composites exposed to $30^{\circ} \mathrm{C}$ and $90 \% \mathrm{RH}$ during the test period correlated to the fungal growth phases with I: Lag phase, II: Exponential phase, III: Decelerating phase and IV: Stationary phase

Table 6 compares the results obtained with the visual evaluation and the image analysis of the 
and from image analysis are close. However, the visual evaluation shows high discrepancy (up to 0.83 $\%)$ due to subjective effect. The image analysis leads to representative values as it is not subject to subjective effect. It seems to be more accurate.

Table 6: Average rating from visual evaluation compared to average rating from image analysis of mold growth on specimens after 12 weeks at $30^{\circ} \mathrm{C}$ and $90 \% \mathrm{RH}$

\begin{tabular}{lccccc}
\hline $\mathbf{N}^{\circ}$ & $\mathbf{C 1}$ & $\mathbf{C 2}$ & $\mathbf{C 3}$ & $\mathbf{C 4}$ & $\mathbf{C 5}$ \\
\hline Visual evaluation & $0.50 \pm 0.76$ & $3.13 \pm 0.83$ & $2.88 \pm 0.64$ & $3.38 \pm 0.74$ & $5.00 \pm 0.00$ \\
Image analysis & 0.00 & 3.13 & 2.93 & 3.43 & 5.00 \\
Rating scale & No fungi & $>50 \%$ & $>25 \%$ & $>50 \%$ & $>75 \%$ \\
\hline
\end{tabular}

\subsection{Microscopic visualizations}

After the test period, a sampling of mold is collected in order to identify the type of fungi, which is responsible for the sample damage. Figure 14 shows some images of contaminated shiv taken using the optical microscope at different magnifications. Table 7 summarizes the fungi characteristics which have contaminated the specimens during the test. In the image 15.a, three species of mold are present. The one which has a long stem with fluffy spherical white head is the Aspergillus ruber (AR). It appears in more detail in the image 15.d. Under these white heads, a bright yellow spherical cleistothecium is hardly discernible. It is Eurotium rubrum (ER), the sexual form of Aspergillus ruber (AR) which is an asexual form. Still under these white heads, shiny smooth black globose pycnidia are slightly visible, which belong certainly to the Phoma sp. genus and could be of the Leptosphaeria maculans (LM) species. These two fungi appear in more detail in the image15.e. In images 15.b and 15.c, only one species is present. At the end of a long stem, there is a large white fan. It is the Penicillium brevicompactum (PB). In the images of the specimens (Figure 8), the colored areas in gray-brown correspond to this fungi. All contaminated composites (from C2 to C5) are infected by these four species of mold.

The fungi are divided in three types of colonizers which need a minimum of available water for fungal growth on the composites surfaces. The available water in the composites is defined by the water activity $\left(a_{w}\right)$ which corresponds to the equilibrium relative humidity $(E R H)$ in percent in the materials. Three colonizers are: primary $\left(a_{w} \leq 0.80\right)$, secondary $\left(0.80<a_{w} \leq 0.90\right)$ and tertiary $\left(0.80<a_{w}\right)[26,27]$. Penicillium brevicompactum (PB), Eurotium rubrum (ER) and Aspergillus ruber (AR) are primary 


\section{ACCEPTED MANUSCRIPT}

461

462

463

464

465

466

467

468

469

470

471

472

473

474

475

colonizers whereas Leptosphaeria maculans (LM) is secondary colonizer and may gradually become the dominant fungi. This means that the fungi belonging to the primary colonizers have appeared as soon as the water activity in the specimens made it possible. The secondary colonizers has appeared later, certainly towards the end of the test as these colonizers needs higher water activity than the primary colonizers $[28,29]$. However, they may create more damage than the primary colonizers because they prefer more complex sugars as cellulose for example [30]. Continuous mass monitoring could have been interesting in order to verify this hypothesis.

Finally, all these molds are potentially allergens. Indeed, these molds are associated with allergic reactions such as allergic rhinitis or worsening of asthma symptoms. The threshold of sensitivity varies from one individual to another, and according to the type of mold for the same person. The individual response and the experienced symptoms vary considerably depending on the individual sensitivity and the duration of exposure to the fungi. Moreover, all molds contain inflammatory substances that can produce inflammation to varying degrees. 


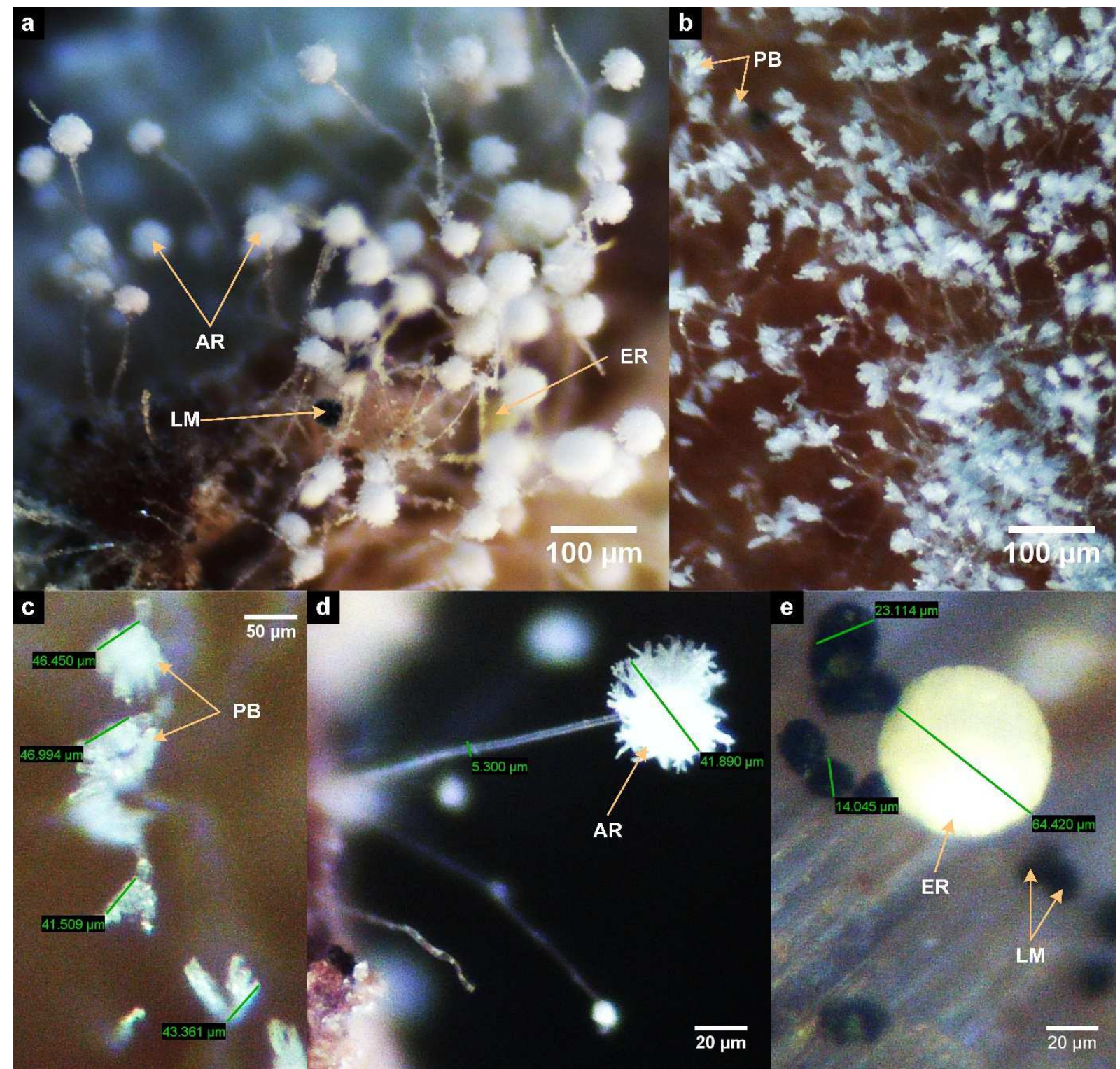

Figure 14: Optical microscope visualizations contaminated surfaces at the 50x ( $a, b$ and $c)$ and 125x (d and e) magnifications (AR: Aspergillus ruber, ER: Eurotium rubrum, LM: Leptosphaeria maculans and PB: Penicillium brevicompactum)

Table 7: Fungi characteristics

$\begin{array}{ccc}\text { Species } & \begin{array}{c}\text { Penicillium } \\ \text { brevicompactum }\end{array} & \begin{array}{c}\text { Eurotium rubrum } \\ \text { (sexual form) }\end{array} \\ \text { Genus } & \text { Penicillium sp. } & \text { Trichocomaceae } \\ \text { Order } & \text { Moniliale } & \text { Eurotiale } \\ \text { Class } & \text { Hyphomycetes } & \text { Eurotiomycetes } \\ \text { Phylum } & \text { Deuteromycota } & \text { Ascomycota }\end{array}$

Can grow between -2 and $30^{\circ} \mathrm{C}$ with an optimum at $23^{\circ} \mathrm{C}$

Microscopic Stipes smooth walled Appearance

\section{Aspergillus ruber (asexual form) \\ Aspergillus sp. Moniliale Hyphomycetes Deuteromycota}

Can grow between 5 and $37^{\circ} \mathrm{C}$ with an optimum at $25^{\circ} \mathrm{C}$

Bright yellow spherical cleistothecium about
White radiate conidial heads

\section{Leptosphaeria maculans \\ (anamorph Phoma lingam) \\ Phoma sp. \\ Sphaeropsidale \\ Coelomycetes \\ Deuteromycota}

Can grow between

15 and $32{ }^{\circ} \mathrm{C}$ with an optimum between 20 and $24^{\circ} \mathrm{C}$

Shiny smooth black globose pycnidium 
in length.

Broad terverticillate penicillin less than 40 $\mu \mathrm{m}$ long and 40 to 50 $\mu \mathrm{m}$ across the phialide tips.

\section{0 to $150 \mu \mathrm{m}$ in} diameter

\section{Mycophenolic acid: Allergens \\ Toxicity}

References

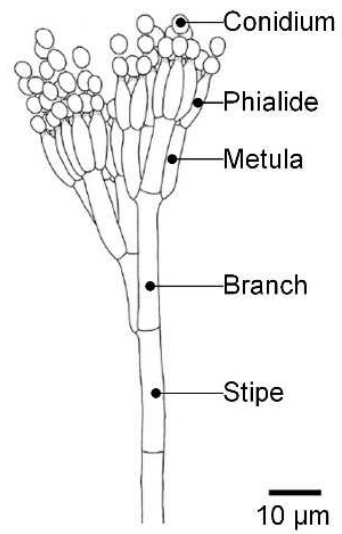

[31-33]

Scheme about 30 to $50 \mu \mathrm{m}$ in diameter.

Stalk smooth until $750 \mu \mathrm{m}$ in length and 5 to $6.5 \mu \mathrm{m}$ in diameter.

\section{Quinonoid pigments:}

Allergens

Allergens

\section{Conclusions}

A protocol for evaluating the resistance to mold contamination of bio-based composites is proposed in this paper. It could be used to assess decay resistance of composites before making them available on the market. Accelerated aging test involves placing the composites in a favorable environment to mold growth for 3 months $\left(30^{\circ} \mathrm{C} ; 90 \% \mathrm{RH}\right)$. Resistance to colonization of composites is then evaluated over time using three tests:

- Monitoring of external surface percentage contaminated by mold;

- Mass monitoring;

- Microscopic analysis.

The test protocol is easily reproducible since it requires commonly available equipment (a climate chamber, a camera and an optical microscope). The analysis protocol differs from existing intrusive fungal growth evaluation methods or based on subjective visual evaluations since it is fully automatized and do not needs any collecting of samples. The non-intrusive image analysis, based on the use of freely available IT-tools associated with mass monitoring allowed a rapid and quantitative assessment of mold growth and composite degradation. 
Mass monitoring overlaps the effect of water absorption and decay. It provides information on long-

term degradation of composites. Moreover, it has been possible to determine the kinetics of apparent mass loss. $\mathrm{C} 1$ composite does not show decay and the specimens increase in mass until they reach equilibrium water content of about $54 \%$ at the end of the test. For C2, C3, C4 and C5 composites, the kinetics of mass loss increase linearly after the first week. This week certainly corresponds to the needed time to obtain a sufficient water content in the specimens in order to trigger mold growth.

The percentage of the external surface contaminated by the composites is monitored by analyzing images of the composites recorded during the test. The proposed method is based on an adaptation of a DIC algorithm. Growth kinetics observed during the test is consistent with what is described in the biology literature and suggests that the proposed method provides consistent and exploitable results. The monitoring of the exterior surface contaminated by the composites allow a rapid and quantitative evaluation of mold growth, essentially during the first 20 days.

The microscopic analysis make it possible to identify the species present on the composite. All identified molds are potential allergens. These are mainly molds from primary colonizers. The observation of a few individuals from secondary colonizers suggests that the degradation process of the composites is still ongoing after 3 months of testing. Indeed, these colonizers would gradually become the dominant fungi if nutrients are still available on the substrate. Moreover, they may create more damage than the primary colonizers because they prefer more complex sugars. Continuous mass monitoring could have been interesting in order to verify this hypothesis.

This test also makes it possible to establish a link between the chemical formulation of the composites and their resistance to fungal colonization. The results suggest that the $\mathrm{pH}$ of given building material is an important predictor of fungal susceptibility. Indeed, C1 formulation is the most resistant to fungal development. This is due to having a surface $\mathrm{pH}$ of 10 . The other formulations have a surface $\mathrm{pH}$ less than or equal to 6 and have a more or less significant fungal development at the end of three months of exposure test at $30^{\circ} \mathrm{C}$ and $90 \% \mathrm{RH}$. Another important predictor is the chemical composition of specimens. However, C3 formulation contains paraffin to increase the water repellence. Thus, the 
water content in the C3 specimens is lower than other specimens leading to lower kinetics of mold

growth on its exposed surface.

\section{Acknowledgements}

This project has received funding from the European Union's Horizon 2020 research and innovation program under grant agreement No. 636835 - The authors would like to thank them.

\section{References}

[1] Nevalainen A, Seuri M. Of microbes and men. Indoor Air 2005;15:58-64. doi:10.1111/j.16000668.2005.00344.x.

[2] Nielsen KF, Holm G, Uttrup LP, Nielsen PA. Mould growth on building materials under low water activities. Influence of humidity and temperature on fungal growth and secondary metabolism. Int Biodeterior Biodegrad 2004;54:325-36. doi:10.1016/j.ibiod.2004.05.002.

[3] Anagnost SE. Wood Decay, Fungi, Stain and Mold 2011.

[4] Hoang CP, Kinney KA, Corsi RL, Szaniszlo PJ. Resistance of green building materials to fungal growth. Int Biodeterior Biodegrad 2010;64:104-13. doi:10.1016/j.ibiod.2009.11.001.

[5] Murtoniemi T, Hirvonen M-R, Nevalainen A, Suutari M. The relation between growth of four microbes on six different plasterboards and biological activity of spores. Indoor Air 2003;13:6573. doi:10.1034/j.1600-0668.2003.01126.x.

[6] Pasanen A-L, Rautiala S, Kasanen J-P, Raunio P, Rantamäki J, Kalliokoski P. The Relationship between Measured Moisture Conditions and Fungal Concentrations in Water-Damaged Building Materials. Indoor Air 2000;10:111-20. doi:10.1034/j.1600-0668.2000.010002111.x.

[7] Yang VW, Clausen CA. Antifungal effect of essential oils on southern yellow pine. Int Biodeterior Biodegrad 2007;59:302-6. doi:10.1016/j.ibiod.2006.09.004.

[8] Ezeonu IM, Price DL, Simmons RB, Crow SA, Ahearn DG. Fungal production of volatiles during growth on fiberglass. Appl Environ Microbiol 1994;60:4172-3.

[9] Klamer M, Morsing E, Husemoen T. Fungal growth on different insulation materials exposed to different moisture regimes. Int Biodeterior Biodegrad 2004;54:277-82. doi:10.1016/j.ibiod.2004.03.016.

[10] Johansson P, Ekstrand-Tobin A, Svensson T, Bok G. Laboratory study to determine the critical moisture level for mould growth on building materials. Int Biodeterior Biodegrad 2012;73:23-32. doi:10.1016/j.ibiod.2012.05.014.

[11] AWPA Standard. E24-06: Standard method of evaluating the resistance of evaluating the resistance of wood product surfaces to mold growth. 2006.

[12] ASTM International. ASTM D3273-12: Standard Test Method for Resistance to Growth of Mold on the Surface of Interior Coatings in an Environmental Chamber. 2012.

[13] British Standards Institute. BSI EN ISO 846: Plastics: Evaluation of the Action of microorganisms. 1997.

[14] Amziane S, Collet F, Lawrence M, Magniont C, Picandet V, Sonebi M. Recommendation of the RILEM TC 236-BBM: characterisation testing of hemp shiv to determine the initial water content, water absorption, dry density, particle size distribution and thermal conductivity. Mater Struct 2017;50:167. doi:10.1617/s11527-017-1029-3.

[15] Rode C, Peuhkuri RH, Mortensen LH, Hansen KK, Time B, Gustavsen A, et al. Moisture buffering of building materials. Technical University of Denmark, Department of Civil Engineering; 2005.

[16] ISOBIO - Naturally High Performance Insulation 2015. http://isobioproject.com/.

[17] Collet F, Prétot S, Lanos C. Hemp-Straw Composites: Thermal And Hygric Performances. Energy Procedia 2017;139:294-300. doi:10.1016/j.egypro.2017.11.211. 
[18] Clausen CA, Yang VW. Image analysis for mould and sapstain detection on wood, Stockholm (Sweden): 2013.

[19] Garzón-Barrero NM, Shirakawa MA, Brazolin S, de Barros Pereira RG de FN, de Lara IAR, Savastano H. Evaluation of mold growth on sugarcane bagasse particleboards in natural exposure and in accelerated test. Int Biodeterior Biodegrad 2016;115:266-76. doi:10.1016/j.ibiod.2016.09.006.

[20] Blaber J, Antoniou A. Ncorr v1.2 n.d. http://www.ncorr.com/index.php/downloads (accessed January 16, 2018).

[21] HOLO3, LMT-Cachan, Airbus Group Innovations. Correli STC. Correli STC n.d. http://www.correli-stc.com/accueil.html (accessed January 16, 2018).

[22] Besnard G, Hild F, Roux S. "Finite-Element" Displacement Fields Analysis from Digital Images: Application to Portevin-Le Châtelier Bands. Exp Mech 2006;46:789-803. doi:10.1007/s11340006-9824-8.

[23] Chu TC, Ranson WF, Sutton MA. Applications of digital-image-correlation techniques to experimental mechanics. Exp Mech 1985;25:232-44. doi:10.1007/BF02325092.

[24] Sutton M, Orteu J-J, Schreier HW. Image Correlation for Shape, Motion and Deformation Measurements. Basic Concepts, Theory and Applications. Springer US. 2009. doi:10.1007/9780-387-78747-3.

[25] Leveau J-Y, LARPENT J-P, BOUIX M. Sécurité microbiologique des procédés alimentaires. Tech Ing Bioprocédés 2001.

[26] Heseltine E, Rosen J, World Health Organization, editors. Who guidelines for indoor air quality: dampness and mould. Copenhagen: 2009.

[27] Stefanowski BK, Curling SF, Ormondroyd GA. A rapid screening method to determine the susceptibility of bio-based construction and insulation products to mould growth. Int Biodeterior Biodegrad 2017;116:124-32. doi:10.1016/j.ibiod.2016.10.025.

[28] Griffith GS, Boddy L. Fungal communities in attached ash (Fraxinus excelsior) twigs. Trans $\mathrm{Br}$ Mycol Soc 1988;91:599-606. doi:10.1016/S0007-1536(88)80033-0.

[29] Li Y, Wadsö L. Fungal activities of indoor moulds on wood as a function of relative humidity during desorption and adsorption processes. Eng Life Sci 2013;13:528-35. doi:10.1002/elsc.201200100.

[30] Sharma PD. Ecology and environment. Rastogi Publications; 2012.

[31] Botton B, Breton A, Fevre M, Guy P, Larpent JP, Veau P. Moisissures utiles et nuisibles: importance industrielle. Paris: Masson; 1985.

[32] Pitt JI, Hocking AD. Fungi and Food Spoilage. Springer Science \& Business Media; 2009.

[33] Visagie CM, Houbraken J, Frisvad JC, Hong S-B, Klaassen CHW, Perrone G, et al. Identification and nomenclature of the genus Penicillium. Stud Mycol 2014;78:343-71. doi:10.1016/j.simyco.2014.09.001.

[34] Teófilo H, Ulloa M. El reino de los hongos: Micología básica y aplicada. Mexico: $2^{\mathrm{a}}$ Edición Fondo de Cultura Económica - UNAM; 1998.

[35] Thom C, Raper KB. The Aspergillus glaucus group. U.S. Dept. of Agriculture; 1941.

[36] Mitrović P. Marinković R. Phoma lingam-a rapeseed parasite in Serbia. Proc 12th Intern Rapeseed Congr. Wuhan China, 2007, p. 217-219.

[37] Smith HC, Sutton BC. Leptosphaeria maculans the ascogenous state of Phoma lingam. Trans $\mathrm{Br}$ Mycol Soc 1964;47:159-IN1. doi:10.1016/S0007-1536(64)80049-8.

[38] Travadon R. Facteurs épidémiologiques contribuant à l'adaptation des populations de Leptosphaeria maculans aux résistances spécifiques de Brassica napus: dispersion des pycnidiospores et des ascospores et progression systémique du champignon. phdthesis. Agrocampus - Ecole nationale supérieure d'agronomie de rennes, 2008. 


\section{ACCEPTED MANUSCRIPT}

$1 \quad$ Figure 1 : Flow-chart of composites production (except C4 formulation)

2 Figure 2 : Developed composites

3 Figure 3: Experimental device for biological aging: conditioning, weighing and photo recording

4 Figure 4: Digital image correlation between initial image f (time $t_{0}$ ) and current image $g$ (time $t$ )

5 Figure 5: Relative brightness, of image $g$ and $f$ : an error involves the detection of a new object.

6 Figure 6: Example of object detection using DIC

$7 \quad$ Figure 7: Procedure of image analysis, DIC and post-treatment applied on composite C5

8 Figure 8: Specimens on the weeks 0, 2, 4, 6, 8 and 12 of ageing test

9 Figure 9: Average rating of mold growth on specimens with the rating scale of BSI EN ISO 846 - 1997 (British 10 Standards Institute, 1997) after 12 weeks at $30^{\circ} \mathrm{C}$ and $90 \% \mathrm{RH}$

11 Figure 10: Variation of mass $\left(\right.$ at $\left.30^{\circ} \mathrm{C}, 90 \% \mathrm{RH}\right)$ from the steady state point at $\left(23^{\circ} \mathrm{C}, 50 \% \mathrm{RH}\right)$, related to the 12 exchange surface area

13 Figure 11: Mass loss for the tested composites during the ageing test

14 Figure 12 : Pictures before and after DIC treatment at the end of the test

15 Figure 13: Image analysis: rating of the contaminated surface of $\mathrm{C2}, \mathrm{C3}, \mathrm{C} 4$ and $\mathrm{C5}$ composites exposed to $30^{\circ} \mathrm{C}$ 16 and $90 \% \mathrm{RH}$ during the test period correlated to the fungal growth phases with I: Lag phase, II: Exponential 17 phase, III: Decelerating phase and IV: Stationary phase

Figure 14: Optical microscope visualizations contaminated surfaces at the 50x ( $a, b$ and c) and 125x (d and e) magnifications (AR: Aspergillus ruber, ER: Eurotium rubrum, LM: Leptosphaeria maculans and PB: Penicillium 20 brevicompactum) 


\section{ACCEPTED MANUSCRIPT}

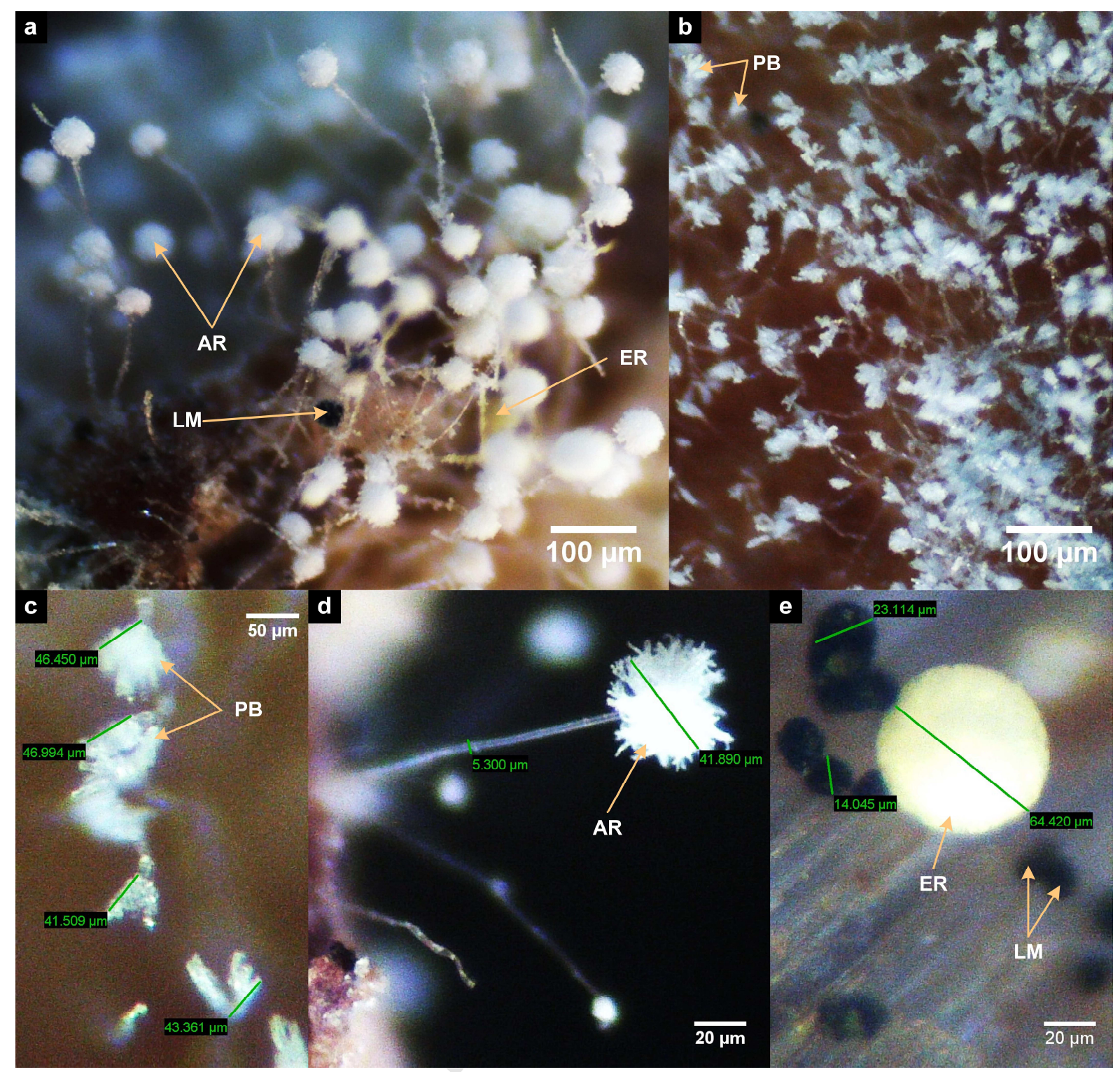




\section{RESEARCH HIGHLIGHTS}

- New rapid method for laboratory scale testing of materials resistance to molds.

- The fungal resistance of new bio-based buildings materials is analyzed.

- Mass monitoring overlaps the effect of water absorption and decay.

- DIC is used to analyze images. Correlation error indicates presence of mold.

- The $\mathrm{pH}$ of given building material is an important predictor of fungal susceptibility. 